\title{
The Soulful Science: What Economists Really Do and Why It Matters
}

Diane Coyle, Princeton University Press, 2007. 288 pages. ISBN 0691125139.

Reviewed by Professor Helen H. Roberts, University of Illinois at Chicago

In 2000 Deirdre McCloskey gathered a series of previously-written pieces as How to Be Human - Though an Economist to prod the profession 'back to scientific and humanistic values' (preface). Diane Coyle's The Soulful Science asserts that the economics profession has made great strides in the past several decades in both these areas. The rest of the world views economists through the old caricatures of unrealistic, mechanistic analysis and sterile mathematical models, so she wrote this book to bring the world up to date. Coyle aims her book at general readers interested in policy, researchers in other disciplines, and economists outside the academy, but it should also interest students and economics teachers with its summaries of research in several Big Idea areas. Those who have not had time to keep up with research in one or more of the book's chosen fields will find a good selection of hard copy and web references to pursue.

The distinctiveness and science of economics derive from how economists create new knowledge with models and data. Economists analyse the world through models, which describe a topic in as succinct a manner as possible (few variables) and specify the relationships among them as clearly as possible. Models are essential so economists can 'confront ... hypotheses and claims with historical evidence' (p. 232). Constructing a testable, falsifiable hypothesis is one of the fundamental skills valued by the economics profession. This way of thinking makes economics a science: the ideal of drawing conclusions only where supported by data. Coyle traces this approach back to David Hume in 1740.

Humanistic values are highlighted by Coyle's choice of topics: happiness, poverty, human irrationality, institutions, society as well as the grand inquiry whether 'economic decisions be interpreted as part of nature, fundamentally evolutionary or biological in nature?' (p.4). Work since the 1980s extends economic insights beyond the 'neoclassical' framework, used by Coyle as shorthand for the basic economic 
model assumptions in the middle of the 20th century. Recent research places economics on a much broader field than the markets-and-money caricature of critics.

The book starts with an exposition of how economists use data to learn about history, characterising some leading researchers as 'passionate nerds' trying to use data to improve the world. The information is livened up with anecdotes such as Stiglitz's eight-hour marathon lecture at Oxford, with which he finished in one day his teaching obligation usually spread over the eight-week term. Coyle notes it was 'no doubt a manifestation of genius' (p.34). Economists may be those without the personality to become accountants, as the old saw goes, but by confronting alternative theories with data they can improve and extend people's lives.

Chapters 2 and 3 consider causes of economic growth and poverty. Neoclassical endogenous growth models (according to Coyle, a tongue-twister intrinsically funny to the British, in another entertaining anecdote), human capital, and technological change models are already providing understanding of how and why some countries grow when others do not, and suggest useful policy changes. Poverty is a harder nut to crack and her conclusion is that research in the details is underway and will make poverty history some day, but that day is not today.

Chapters 5 and 6 look at developments in the foundations of microeconomics, utility and decisions by individuals and aggregating humans into markets. By page 172 , Coyle cautions us against throwing out the markets baby with the unbounded rationality and universal-perfect-competition bathwater as we draw up breathless with this sentence:'The paradox of information economics is that pervasive asymmetries of information mean that markets are flawed, and yet markets in many circumstances remain better mechanisms for sharing and diffusing information than any alternative social institution we've yet devised.' Hayek's points about the role of information are nicely summarised. Economics has not and should not abandon markets.

Chapters 7 and 8 build from the microfoundations by placing humans into society. Here the soulfulness of economics really comes into focus, as economists model human concerns: society, institutions, culture and networks. A minor quibble: one of the dangers of an overview of multiple research areas is the example noted of the dominant QWERTY keyboard. Coyle cites research implying market failure (network externalities) caused the QWERTY keyboard's dominance. That has been disputed and may not be so settled. For a summary and references on the current status of this issue, see the 'Path Dependence' article in the EH.Net Encyclopedia.

Chapter 9 is titled 'Why Economics has Soul', but what it gives us is a way to distinguish economists from others (economists use models to explain the world), a 
summary of critiques of mainstream economics (that it is mechanistic, too mathematical, not connected to the real world, reactionary, etc.), a defence of economics, and finally a plea to include even more of these 'best practices' in the textbooks.

I have used Coyle's previous book, Sex, Drugs and Economics in beginning economics classes. Her gift for memorable examples meant that even when we had not discussed assigned readings in class, students remembered and used them to bolster their arguments months later in their final exams. Soulful Science's anecdotes and quips enliven the not-so-simple discussion throughout. Models are stories, but the personal vignettes make the book sing and may help us 'passionate nerds' get through our lectures better - and a few cocktail parties as well.

\section{References}

Coyle, D. (2004) Sex, Drugs \& Economics: An Unconventional Introduction to Economics. New York:Thomson Texere.

McCloskey, D. (2000) How to Be Human - Though Economist. Ann Arbor: University of Michigan Press.

Puffert, D. (2008) 'Path Dependence'. EH.Net Encyclopedia, edited by Robert Whaples. 10 February 2008. http://eh.net/encyclopedia/article/puffert.path.dependence.

Accessed June 15, 2008.

Reviewed by

Helen H. Roberts

Clinical Associate Professor and Associate Director

UIC Center for Economic Education

601 Capital S. Morgan 709 (m/c 144)

Chicago, IL 60607-7121

USA

Email: hroberts@uic.edu 